\title{
Curcumin-induced histone acetylation inhibition improves stress-induced gastric ulcer disease in rats
}

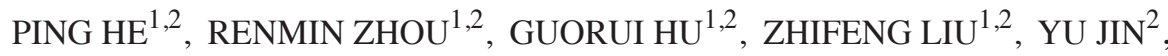 \\ GUANG YANG ${ }^{2}, \mathrm{MEI} \mathrm{LI}^{2}$ and QIAN LIN ${ }^{2}$ \\ ${ }^{1}$ Department of Pediatrics, Medical College of Nanjing University, Nanjing, Jiangsu 210093; ${ }^{2}$ Department of Digestive Disease, \\ Nanjing Children's Hospital, Nanjing Medical University, Nanjing, Jiangsu 210008, P.R. China
}

Received January 9, 2014; Accepted October 24, 2014

DOI: $10.3892 / \mathrm{mmr} .2014 .2958$

\begin{abstract}
Curcumin is known to possess anti-inflammatory properties. Despite the fact that curcumin is known to be a strong inhibitor of $\mathrm{H}^{+}, \mathrm{K}^{+}$-ATPase activity, the mechanism underlying the curcumin-induced inhibition of the transcription of the $\mathrm{H}^{+}, \mathrm{K}^{+}$-ATPase $\alpha$ subunit in gastric mucosal parietal cells remains unclear. The present study investigated the possible mechanism by which curcumin inhibits stomach $\mathrm{H}^{+}, \mathrm{K}^{+}$-ATPase activity during the acute phase of gastric ulcer disease. A rat model of stress-induced gastric ulcers was produced, in which the anti-ulcer effects of curcumin were examined. Curcumin-induced inhibition of the $\mathrm{H}^{+}, \mathrm{K}^{+}$-ATPase promoter via histone acetylation, was verified using a chromatin immunoprecipitation assay. The results showed that curcumin improved stress-induced gastric ulcer disease in rats, as demonstrated by increased $\mathrm{pH}$ values and reduced gastric mucosal hemorrhage and ulcer index. These effects were accompanied by a significant reduction in the level of histone $\mathrm{H} 3$ acetylation at the site of the $\mathrm{H}^{+}, \mathrm{K}^{+}$-ATPase promoter and in the expression of the gastric $\mathrm{H}^{+}, \mathrm{K}^{+}$-ATPase $\alpha$ subunit gene and protein. In conclusion, curcumin downregulated the acetylation of histone $\mathrm{H} 3$ at the site of the $\mathrm{H}^{+}, \mathrm{K}^{+}$-ATPase promoter gene, thereby inhibiting the transcription and expression of the $\mathrm{H}^{+}$, $\mathrm{K}^{+}$-ATPase gene. Curcumin was shown to have a preventive and therapeutic effect in gastric ulcer disease.
\end{abstract}

\section{Introduction}

Disorders of gastric acid include gastroesophageal reflux disease, functional dyspepsia, peptic ulcers and chronic gastritis. The judicious administration of antacids is a key component of the successful treatment of these diseases.

Correspondence to: Dr Zhifeng Liu, Department of Digestive Disease, Nanjing Children's Hospital, Nanjing Medical University, 22 Hankou Road, Nanjing, Jiangsu 210008, P.R. China

E-mail: liuzfnj@hotmail.com; liu8917@163.com

Key words: curcumin, gastric ulcer, $\mathrm{H}^{+}, \mathrm{K}^{+}$-ATPase, histone $\mathrm{H} 3$
Antacids alleviate heartburn, acid reflux and other symptoms of acid-related diseases quickly and effectively, controlling the disease and improving quality of life. The gastric mucosal parietal cells' proton pump, termed $\mathrm{H}^{+}, \mathrm{K}^{+}$-ATPase, is the key enzyme in the later stages of gastric acid secretion. Treatment with proton pump inhibitors (PPIs) inhibits the activity of the $\mathrm{H}^{+}, \mathrm{K}^{+}$-ATP enzyme, which effectively reduces gastric acid secretion (1). However, studies have shown that the prolonged of PPIs may lead to an increased risk of an infection due to the suppression of stomach acid, which ordinarily acts as the first line of defense. In addition, long-term use of PPIs increases the risk of a number of other side effects, such as the development of hyperplastic polyps and a reduction in the absorption of certain trace elements and vitamins (2-4). Therefore, it is necessary to investigate novel anti-ulcer drugs with non-toxic side effects, which may replace antacids.

In recent years, there has been growing evidence for the potential of curcumin as a safe and effective anti-ulcer treatment. $(5,6)$. Curcumin is a polyphenol, derived from the plant Curcuma longa, and has also been investigated as a promising therapy for cancer, infection and dementia (7-9). A number of studies have found that curcumin strongly inhibits the activity of $\mathrm{H}^{+}, \mathrm{K}^{+}$-ATPase $(10,11)$, which indicated that curcumin may be a potential prophylactic and therapeutic agent in gastric ulcer disease. However, the mechanism by which curcumin inhibits the transcription of the $\mathrm{H}^{+}, \mathrm{K}^{+}$-ATPase $\alpha$ subunit, present in gastric mucosal parietal cells, remains unclear. A study reported that this effect may be driven by histone acetylation of the $\mathrm{H}^{+}, \mathrm{K}^{+}$-ATPase $\alpha$ subunit (12). Recently, studies have shown that curcumin may be used as an inhibitor of typical histone acetyltransferase (HAT), as it is able to directly inhibit the activity of HAT $(13,14)$. Thus, it was hypothesized that curcumin inhibits the transcription of the $\mathrm{H}^{+}, \mathrm{K}^{+}$-ATPase $\alpha$ subunit via the inhibition of histone acetylation.

\section{Materials and methods}

Chemicals and reagents. Curcumin [1,7-bis(4-hydroxy-3-meth oxyphenyl)-1,6-heptadiene-3,5-dione; $>95 \%$ purity] was manufactured by the Nanjing Zelang Biological Pharmaceutical Co., Ltd. (Nanjing, China). Ursodeoxycholic Acid (UDAC; >99\% purity) was obtained from Dr. Falk Pharma GmbH. (Freiburg, Germany). Rabbit polyclonal anti-acetyl-histone H3 antibody 
(dilution, 1:800; catalog number, 06-599) was obtained from Cell Signaling Technology, Inc., (Danvers, MA, USA), monocolonal anti- $\mathrm{H}^{+}, \mathrm{K}^{+}$-ATPase $\alpha$ subunit antibody (dilution, 1:500; catalog number, 119101) was obtained from Merck Millipore (Darmstadt, Germany), anti-actin monoclonal antibody (dilution, 1:1,000; catalog number, 130656 and monoclonal alkaline phosphatase (AP)-conjugated anti-rabbit and anti-mouse IgG antibodies (dilution, 1:1000; catalog number, 2372,2373) were obtained from Santa Cruz Biotechnology, Inc. (Dallas, TX, USA).

Animals and treatment. Male adult Sprague-Dawley rats (age, 6-7 weeks; weight, 200-250 g) were obtained from the Animal Experimental Center, Drum-Tower Hospital, Nanjing University (Nanjing, China). The temperature of the laboratory in which the animals were kept was maintained at $23 \pm 2^{\circ} \mathrm{C}$, with a humidity of 40-60\%. Rats were provided with a standard diet and drinking water ad libitum, and were acclimated to the environment for seven days prior to the experiments. Animals were fasted for $24 \mathrm{~h}$, with access to water ad libitum, and deprived of water $1 \mathrm{~h}$ prior to the experiment. Forty male SD rats were divided randomly into four groups of ten: Control group, ulcer model group, curcumin group and UDAC group. UDAC, a typical inhibitor of HAT, was regarded as a positive control. All animals, other than those in the control group, were subjected to a water immersion-restraint stress (WRS) model as described previously (15). The curcumin and UDAC groups received curcumin (20 mg/kg, p.o.) or UDAC (30 mg/kg, p.o) for seven consecutive days prior to delivery of WRS, respectively. All animal procedures were approved by the Animal Care Ethics Committee of Nanjing University Medical School and Nanjing Drum-Tower Hospital, and performed in accordance with Guide for the Care and Use of Laboratory Animals (NIH publication 85-23 revised 1996, USA).

Measurement of gastric acid $\mathrm{pH}$. Rats were anesthetized with valium (Shanghai Xinyi pharmaceutical Co., Ltd., Shanghai, China) and ketamine (Zhejiang Juxu Pharmaceutical Co., Ltd., Jinhua, China) mixed liquor (10 ml/kg intraperitoneally). A midline laparotomy was performed and the stomach was exposed. The pylorus and cardia were ligated, and the $\mathrm{pH}$ electrode of the $\mathrm{pH} / \mathrm{mV}$ meter (Sartorius AG, Shanghai Branch, Shanghai, China) was inserted into the stomach lumen in order to measure the $\mathrm{pH}$ value.

Evaluation of gastric mucosal ulcer index (UI). Following measurement of the gastric acid $\mathrm{pH}$, the stomach was opened along the greater curvature and rinsed with $0.9 \%$ ice-cold normal saline. The stomach was then examined under $\mathrm{x} 10$ magnification in order to observe and score erosions. The following categories were used for scoring: 1, small round hemorrhagic erosion; 2 , hemorrhagic erosion of $<1 \mathrm{~mm} ; 3$, hemorrhagic erosion of 1-2 $\mathrm{mm} ; 4$, hemorrhagic erosion of 2-4 mm; and 5, hemorrhagic erosion of $>4 \mathrm{~mm}$. The score was multiplied by 2 when the width of erosion was $>1 \mathrm{~mm}$ (16).

Histology and morphology. Following evaluation of the gastric mucosal ulcer index, $1.0 \times 1.0 \mathrm{~cm}$ areas with the most obvious damage in the stomach were excised and fixed in $4 \%$ neutral formaldehyde $24 \mathrm{~h}$. Paraffin sections $(5 \mu \mathrm{m})$ were prepared and stained with Mayer's hematoxylin and eosin according to standard procedures. All histopathological changes were observed under a light microscope (Biological microscope XSP - 460; Shanghai Zhongheng Instrument Co., Ltd., Shanghai, China).

Quantification of $\mathrm{H}^{+}, \mathrm{K}^{+}$-ATPase mRNA. Stomach RNA was extracted using TRIzol ${ }^{\circledR}$ reagent (Invitrogen Life Technologies, Carlsbad, CA, USA), and was used for reverse transcription with the Primescript RT reagent kit (Takara Bio, Inc., Shiga, Japan) according to the manufacturer's instructions. Quantitative polymerase chain reaction (qPCR) was performed with $1 \mu \mathrm{l}$ cDNA in total volume of $10 \mu \mathrm{l}$ with the SYBR Premix Ex Taq II (Takara Bio, Inc.) according to the manufacturer's instructions. Relative gene expression was normalized to that of an internal $\beta$-actin control. Primers were designed according to Genewiz, Inc., Suzhou, China). The following primers were used: Forward: 5'-ATCATTGGACGCATCGCCTCTCTGG-3' and reverse: 5'-GTCTTCTGTGGTGTCCGCCGTGTGG-3' for the $\mathrm{H}^{+}, \mathrm{K}^{+}$-ATPase $\alpha$ subunit, and forward: 5'-AACACCCCAGCCATGTACG-3' and reverse: 5'-ATG TCACGCACGATTTCCC-3' for $\beta$-actin. The following conditions were used for PCR: An initial denaturation step at $94^{\circ} \mathrm{C}$ for $3 \mathrm{~min}$, followed by 30 cycles, consisting of denaturation at $94^{\circ} \mathrm{C}$ for $20 \mathrm{sec}$, annealing at $53^{\circ} \mathrm{C}$ for $45 \mathrm{sec}$, extension at $72^{\circ} \mathrm{C}$ for $50 \mathrm{sec}$ and a final extension step at $72^{\circ} \mathrm{C}$ for $7 \mathrm{~min}$, followed by cooling to $25^{\circ} \mathrm{C}$ for $5 \mathrm{~min}$. The fold change in the expression of $\mathrm{H}^{+}, \mathrm{K}^{+}$-ATPase $\alpha$ subunit in each group relative to that of $\beta$-actin was calculated following the formula: $2^{(\Delta \mathrm{Ct}}$ of gene $-\Delta$ Ct of actin)

Western blot analysis of acetyl-histone and $\mathrm{H}^{+}, \mathrm{K}^{+}$-ATPase protein. To extract the $\mathrm{H}^{+}, \mathrm{K}^{+}$-ATPase protein, gastric mucosa were lysed in ice-cold radioimmunoprecipitation assay (RIPA) buffer (Santa Cruz Biotechnology, Inc.) supplemented with a protease inhibitor mixture (PMSF and aprotinin; Nanjing Dingguo Biotechnology Co., Ltd., Nanjing, China) for $30 \mathrm{~min}$, then the homogenate was vortexed, sonicated briefly on ice and centrifuged at $14,000 \mathrm{x}$ for $20 \mathrm{~min}$ at $4^{\circ} \mathrm{C}$. The supernatant was removed and total protein was measured using the bicinchoninic acid (BCA) kit (Beyotime Biotech Co., Ltd., Shanghai, China). In order to extract histones, gastric mucosa were lysed in ice-cold RIPA buffer supplemented with a protease inhibitor mixture (PMSF and aprotinin) for $30 \mathrm{~min}$. The sample was then collected and centrifuged at $12,000 \mathrm{x} \mathrm{g}$ at $4^{\circ} \mathrm{C}$ for $25 \mathrm{~min}$. The pellet was washed once in buffer $(10 \mathrm{mM}$ Tris-Cl, pH 7.4; and 13 mm EDTA; (Nanjing SunShine Biotechnology Co., Ltd., Nanjing, China) and resuspended in $200 \mu \mathrm{l}$ of $0.25 \mathrm{M} \mathrm{HCl}$. Following incubation on ice for $90 \mathrm{~min}$, the sample was centrifuged at $13,000 \mathrm{x}$ g for $15 \mathrm{~min}$ at $4^{\circ} \mathrm{C}$. The supernatant was mixed with $1 \mathrm{ml}$ cold acetone and kept at $-20^{\circ} \mathrm{C}$ overnight. Histones were collected by centrifugation at $14,000 \mathrm{x} \mathrm{g}$ at $4^{\circ} \mathrm{C}$ for $15 \mathrm{~min}$. Following one wash with acetone, the histones were air-dried and resuspended in $4 \mathrm{M}$ urea (Nanjing Sunbeijia Biotechnology Co., Ltd., Nanjing, China). Protein was measured using a BCA kit.

Equal quantities of protein were used in each lane of loaded sample. The protein blots were blocked with $5 \%$ milk in Tris-buffered saline with Tween-20 buffer (Nanjing Saihongrui Biotechnology Co., Ltd., Nanjing, China) overnight at $4^{\circ} \mathrm{C}$ and then incubated for $1 \mathrm{~h}$ or overnight with 

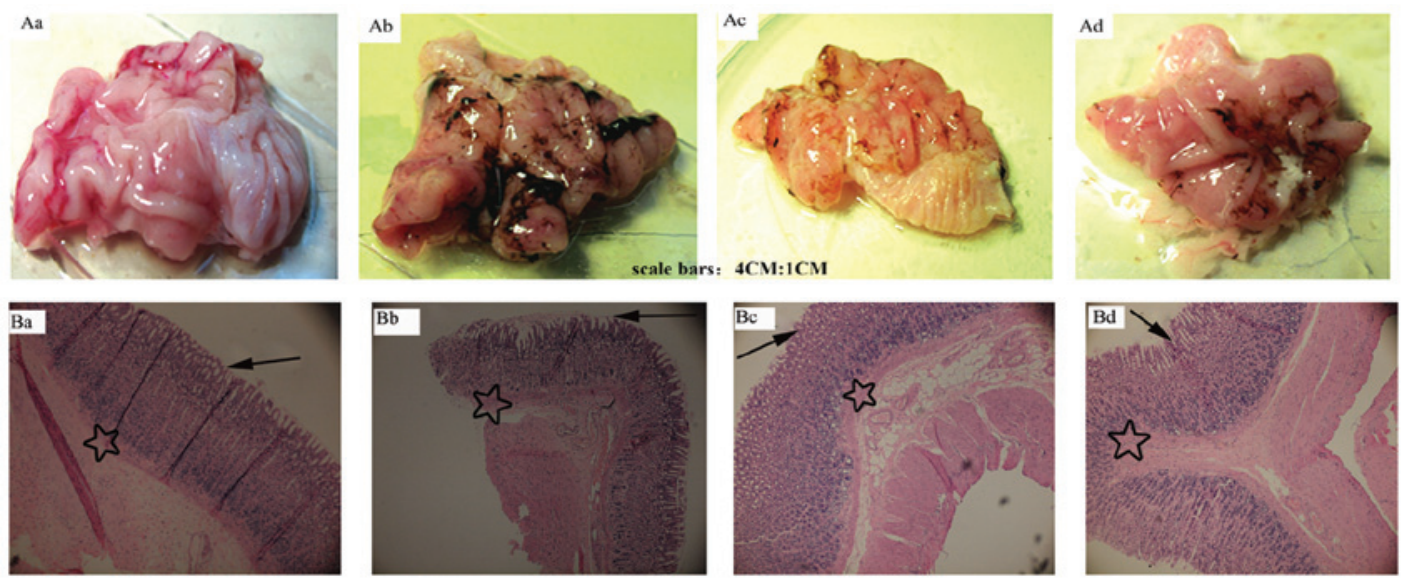

Figure 1. Effect of curcumin on macroscopic and microscopic changes in the gastric mucosa, induced by water-immersion and restraint stress in rats. The upper panel (A) represents macroscopic morphological changes (gross observation) and the lower panel (B) illustrates microscopic histopathological observation (magnification, $\mathrm{x} 40$ ). (Aa and $\mathrm{Ba}$ ) Control group; (Ab and $\mathrm{Bb}$ ) gastric ulcer model group (induced by water-immersion and restraint stress following pretreatment with $2 \mathrm{ml}$ normal saline); (Ac and Bc) curcumin group, underwent water-immersion and restraint stress following pretreatment with $20 \mathrm{mg} / \mathrm{kg}$ curcumin dissolved in saline; and (Ad and Bd) UDAC group, underwent water-immersion and restraint stress following pretreatment with 30 mg/kg UDAC. Epithelial and mucosal layers are indicated by arrows and stars, respectively. UDAC, ursodeoxycholic acid.

antibodies against anti-acetyl-histone $\mathrm{H} 3$ (1:800 dilution), the $\mathrm{H}^{+}, \mathrm{K}^{+}$-ATPase $\alpha$ subunit (1:500 dilution) and $\beta$-actin (1:1,000 dilution). Following washes of the protein blots, incubation with AP-conjugated anti-rabbit or anti-mouse IgG antibody for another 90 mins was conducted. Following incubation and thorough washes, BCIP/NBT reagents (Sigma-Aldrich, St. Louis, MO, USA) were used for the development of colorimetric signals on the membranes.

Chromatin immunoprecipitation (ChIP) analysis. ChIP assays were performed using EZ ChIP Chromatin Immunoprecipitation kit (Merck, Millipore; 17-371) according to the manufacturer's instructions. DNA was crosslinked with formaldehyde (final concentration, $1 \%$, for $10 \mathrm{~min}$ ). This process was terminated by washing the cells with $4 \mathrm{ml}$ of $1.25 \mathrm{M}$ glycine solution (Nanjing SunShine Biotechnology Co., Ltd.). Gastric mucosa were lysed in the presence of protease inhibitors and the lysates were sonicated using Scientz JY98-IIIDN (Scientz Biotechnology Co., Ltd., Ningbo, China) in order to shear DNA (average size 200-1,000 bp). Immunoprecipitations were performed using $5 \mu \mathrm{g}$ rabbit-anti-acetyl-histone $\mathrm{H} 3$ and $5 \mu \mathrm{g}$ of normal rabbit IgG (included in the EZ ChIP kit). The antibody-chromatin complex was precipitated by adding protein $\mathrm{G}$ agarose (Merck, Millipore; 17-371), incubated for 4-6 h by rotating at $48^{\circ} \mathrm{C}$ and centrifuged at 3,000 x $\mathrm{g}$ for $5 \mathrm{~min}$. Input DNA was regarded as a positive control, rabbit IgG (r-IgG), or mouse IgG (m-IgG) purified DNA served as a negative control for all the experiments. DNA purification was conducted using spin columns. Immunoprecipitated DNA was then subjected to PCR, using the following primers: Forward: 5'-GACATCGGTCTGCACAAAGCA-3' and reverse: 5'-AAGTATTGGGCACAGTCACCT-3' for acetyl-histone binding $\mathrm{H}^{+}, \mathrm{K}^{+}$-ATPase, which generated DNA fragments of $676 \mathrm{bp}$. PCR was conducted under the following conditions: $94^{\circ} \mathrm{C}$ for $3 \mathrm{~min},\left(94^{\circ} \mathrm{C}\right.$ for $20 \mathrm{sec}, 50^{\circ} \mathrm{C}$ for $30 \mathrm{sec}$ and $72^{\circ} \mathrm{C}$ $30 \mathrm{sec}$ ) all for 32 cycles, and then $72^{\circ} \mathrm{C} 5 \mathrm{~min}$. PCR products were separated on a $1 \%$ agarose gel and stained with cyanine dye (Tianjin Biolite Biotech Co., Ltd, Tianjin, China).
Table I. pH value of gastric juice and ulcer index of gastric mucosa in all groups.

\begin{tabular}{lccc}
\hline Group & No. & $\begin{array}{c}\text { Gastric ulcer } \\
\text { index }\end{array}$ & $\begin{array}{c}\text { Gastric juice } \\
\text { pH value }\end{array}$ \\
\hline Control & 10 & 0 & $3.32 \pm 0.29$ \\
Ulcer model & 10 & $33.60 \pm 2.46^{\mathrm{a}}$ & $1.85 \pm 0.31^{\mathrm{a}}$ \\
Curcumin & 10 & $22.20 \pm 2.78^{\mathrm{b}}$ & $2.49 \pm 0.39^{\mathrm{b}}$ \\
UDAC & 10 & $20.30 \pm 2.13^{\mathrm{b}}$ & $2.51 \pm 0.41^{\mathrm{b}}$ \\
\hline
\end{tabular}

${ }^{\mathrm{a}} \mathrm{P}<0.01$, compared with the control groups and ${ }^{\mathrm{b}} \mathrm{P}<0.05$, compared with the gastric ulcer model groups, $\mathrm{n}=10$. UDAC, ursodeoxycholic acid.

Statistical analysis. Data are expressed as the mean \pm standard error of the mean of ten animals in each group. The data were analyzed using SPSS 18.0 software (SPSS, Inc., Chicago, IL, USA). Groups were compared using one-way analysis of variance followed by Student-Newman-Keul's multiple comparisons. $\mathrm{P}<0.05$ was considered to indicate a statistically significant difference.

\section{Results}

Effect of curcumin on $\mathrm{pH}$ value, gastric mucosa and UI of gastric mucosa in rats. Compared with the control group, the UI increased and the $\mathrm{pH}$ value decreased significantly in the ulcer model group (Table I). Compared with the ulcer model group, the UI decreased and the $\mathrm{pH}$ value increased significantly in the curcumin group. No significant difference was detected in UI and $\mathrm{pH}$ values between the curcumin UDAC groups. Gastric mucosal hemorrhage and ulceration were observed using light microscopy in the ulcer model group. However, rats pretreated with curcumin displayed a marked attenuation of the histopathological changes induced by stress (Fig. 1). 


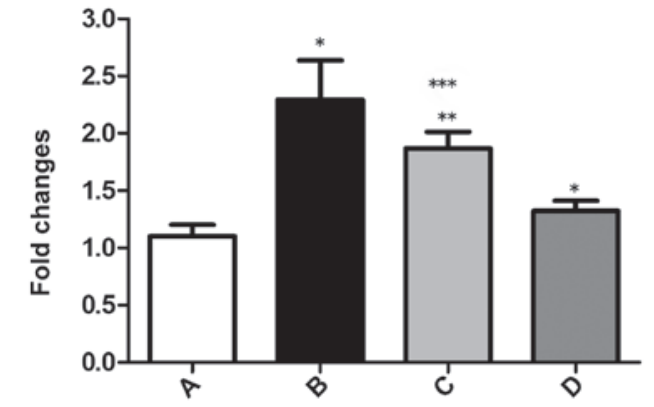

Figure 2. Effect of curcumin on the expression of $\mathrm{H}^{+}, \mathrm{K}^{+}$-ATPase $\alpha$ subunit mRNA. Reverse transcription-quantitative polymerase chain reaction was performed to examine the RNA transcript levels of $\mathrm{H}^{+}, \mathrm{K}^{+}$-ATPase. (A) Control group. (B) Gastric ulcer model group. (C) Curcumin group. (D) UDAC group. Similar results were obtained in three independent sets of experiments. Data are presented as the mean \pm standard error of the mean $(n=3) .{ }^{*} \mathrm{P}<0.01$, compared with the control group, ${ }^{* *} \mathrm{P}<0.05$, compared with the gastric ulcer model group and ${ }^{* * *} \mathrm{P}>0.05$ compared with the UDAC group.
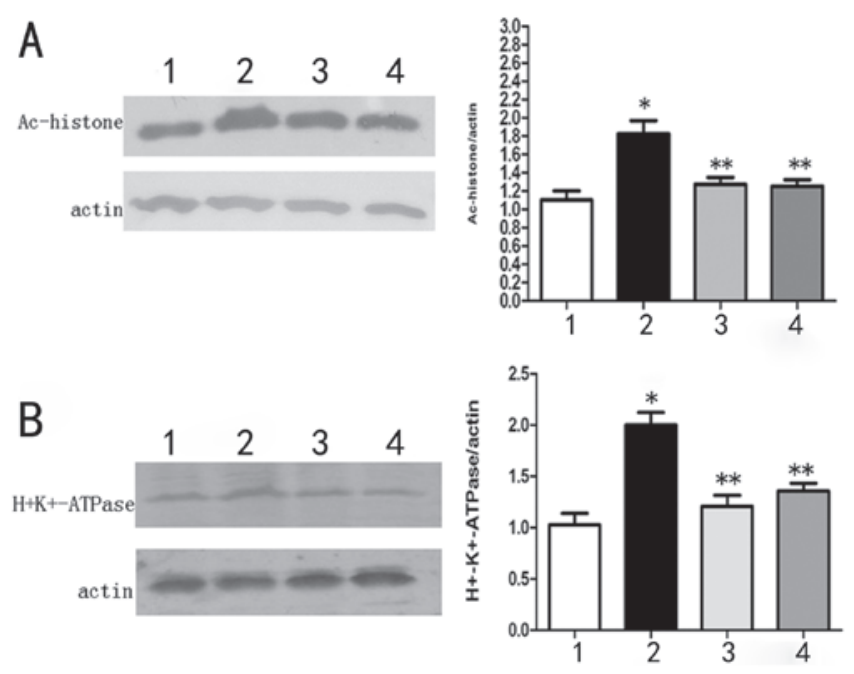

Figure 3. Western blot analysis of total Ac-histone $\mathrm{H} 3$ and $\mathrm{H}^{+}, \mathrm{K}^{+}$-ATPase in the rat gastric mucosa. (A) Representative western blot of total Ac-histone $\mathrm{H} 3$ $\mathrm{H}^{+}, \mathrm{K}^{+}$-ATPase levels in the rat gastric mucosa. (B) Representative western blot of total $\mathrm{H}^{+}, \mathrm{K}^{+}$-ATPase levels in the rat gastric mucosa. Lane 1, control group; lane 2, gastric ulcer model group; lane 3, curcumin group; and lane 4, ursodeoxycholic acid group. Similar results were obtained in three independent sets of experiments. ${ }^{*} \mathrm{P}<0.01$, compared with the control group and ${ }^{* *} \mathrm{P}<0.05$, compared with the gastric ulcer model group, $\mathrm{n}=3$.

Effect of curcumin on $\mathrm{H}^{+}, \mathrm{K}^{+}$-ATPase $m R N A$. In contrast to the control group, gastric mucosal damage was observed following WRS, which contributed to the increased expression of $\mathrm{H}^{+}, \mathrm{K}^{+}$-ATPase mRNA (Fig. 2). The expression of $\mathrm{H}^{+}, \mathrm{K}^{+}$-ATPase mRNA in the group treated with curcumin was significantly lower than that in the ulcer model group, which indicates that curcumin suppresses $\mathrm{H}^{+}, \mathrm{K}^{+}$-ATPase mRNA expression.

Change in histone $\mathrm{H} 3$ acetylation and $\mathrm{H}^{+}, \mathrm{K}^{+}$-ATPase by curcumin treatment in the rat gastric mucosa. The expression of acetyl-histone $\mathrm{H} 3$ was significantly higher in the ulcer model group than that in the control group. Compared with the ulcer model group, acetyl-histone $\mathrm{H} 3$ was significantly downregulated in the curcumin group (Fig. 3A). In addition, the expression of the $\mathrm{H}^{+}, \mathrm{K}^{+}$-ATPase protein was significantly greater in the ulcer
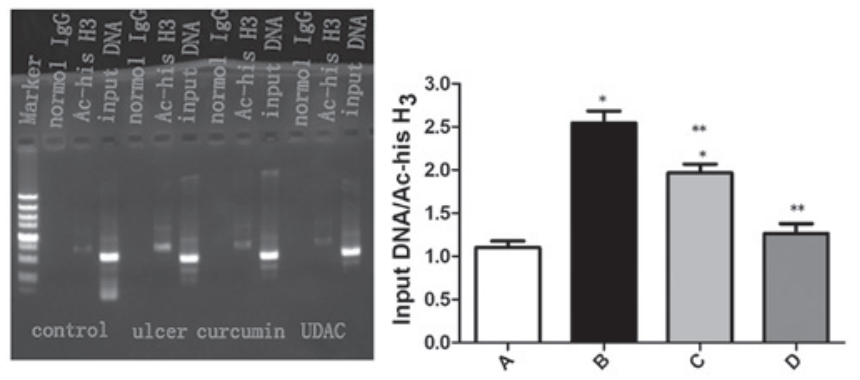

Figure 4. Acetylation of histone $\mathrm{H} 3$ at the site of the $\mathrm{H}^{+}, \mathrm{K}^{+}$-ATPase promoter gene in gastric mucosa following treatment with curcumin was detected by a chromatin immunoprecipitation assay. Left panel: Representative levels of acetylation of histone $\mathrm{H} 3$ at the site of $\mathrm{H}^{+}, \mathrm{K}^{+}$-ATPase promoter gene in the rat gastric mucosa. Right panel: Densitometric analysis of histone acetylation normalized by input. Lane A, control group; lane B, gastric ulcer model group; lane C, curcumin group; and lane D, UDAC group. Similar results were obtained in three independent sets of experiments. ${ }^{*} \mathrm{P}<0.01$, compared with the control group and ${ }^{* *} \mathrm{P}<0.05$, compared with the gastric ulcer model groups, $\mathrm{n}=3$. UDAC, ursodeoxycholic acid.

model group than it was in the control group. Compared with the ulcer model group, the level of the $\mathrm{H}^{+}, \mathrm{K}^{+}$-ATPase protein was significantly downregulated in the curcumin group (Fig. 3B). No significant difference in acetyl-histone $\mathrm{H} 3$ and $\mathrm{H}^{+}, \mathrm{K}^{+}$-ATPase levels were detected between the curcumin UDAC groups.

Change in the acetylation of histone $H 3$ at the site of $\mathrm{H}^{+}, \mathrm{K}^{+}$-ATPase promoter gene in gastric mucosa following treatment with curcumin. Compared with the control group, acetylation of histone $\mathrm{H} 3$ at the site of the $\mathrm{H}^{+}, \mathrm{K}^{+}$-ATPase promoter was significantly increased in the ulcer model group. Compared with the ulcer model group, acetylation of histone $\mathrm{H} 3$ at the site of the $\mathrm{H}^{+}, \mathrm{K}^{+}$-ATPase promoter was significantly decreased in the curcumin group (Fig. 4). These data suggest that curcumin inhibits histone $\mathrm{H} 3$ acetylation at the site of the $\mathrm{H}^{+}, \mathrm{K}^{+}$-ATPase promoter in gastric mucosal cells.

\section{Discussion}

Stress ulcers (SU), also termed acute gastric mucosal lesions, are superficial mucosal lesions that are located predominantly in the fundus of the stomach. Gastric acid is an endogenous host defense, which is involved in the development of SU. The final step in gastric acid secretion is the exchange of $\mathrm{H}^{+}$ and $\mathrm{K}^{+}$by the parietal cell proton pump (the $\mathrm{H}^{+}, \mathrm{K}^{+}$-ATPase). The $\mathrm{H}^{+}, \mathrm{K}^{+}$-ATPase of the gastric parietal cell is therefore a critical component of the ion transport system, which mediates acid secretion in the stomach. $\mathrm{H}^{+}, \mathrm{K}^{+}$-ATPase consists of two subunits, an $\alpha$-subunit (gene locus Atp4a) and a $\beta$-subunit (gene locus Atp4b). The $\alpha$-subunit contains ATP and cation binding sites, and is required for the catalytic and transport functions of the enzyme (17). PPIs accumulate in the parietal cells and are translated into sulfonamide. Sulfonamide bonds with the disulfide of the $\mathrm{H}^{+}, \mathrm{K}^{+}$-ATPase $\alpha$ subunit, thereby blocking the secretion of stomach acid. A previous study reported that ablation of the $\mathrm{H}^{+}, \mathrm{K}^{+}$-ATPase $\alpha$ subunit resulted in achlorhydria and hypergastrinemia. Disturbances in the secretory membranes of the parietal cell and metaplasia of the gastric mucosa, indirectly demonstrated that the 
$\mathrm{H}^{+}, \mathrm{K}^{+}$-ATPase $\alpha$ subunit is correlated with the development of gastric acid-related diseases (17).

In the present study, the establishment of a rat ulcer model was verified through assessment of the gastric acid $\mathrm{pH}$ value, the UI, and histological and pathological changes. Compared with the control group, the UI increased and $\mathrm{pH}$ values decreased significantly in the ulcer model group. Compared with the ulcer model group, the UI decreased and the $\mathrm{pH}$ values increased significantly in the curcumin group. Gastric mucosal hemorrhage and ulceration were observed under a light microscope in the ulcer model group. In the curcumin group, gastric mucosa damage was observed, but to a lesser degree, and there was no visible ulceration. No significant difference was detected in UI or $\mathrm{pH}$ values between the curcumin UDAC groups.

Curcumin is a well-known dietary pigment, derived from the plant Curcuma longa. Previous studies have indicated that it exhibits anti-infection properties (8) and has the ability to inhibit inflammatory cell proliferation, invasion, and angiogenesis, through numerous molecular targets and mechanisms of action $(18,19)$. Curcumin has been shown to reduce gastric acid production and concentration (20). WRS has been reported to produce band-like hemorrhagic lesions in the glandular portion of the stomach (21). The current study showed that curcumin increased $\mathrm{pH}$ value, and reduced gastric mucosal damage and $\mathrm{UI}$ in a rat model of gastric ulcer disease. The results also suggested that inhibition of histone acetylation is a possible novel mechanism explaining these effects of curcumin. Studies have demonstrated that curcumin has a protective effect on stomach disease due to a variety of causes $(5,22)$. A study by Tuorkey and Karolin (22) found that curcumin exerted a protective effect against gastric ulcer development; the anti-ulcer activity of curcumin was demonstrated by the attenuation of certain mediators of ulceration, including gastric acid hypersecretion, total peroxides, myeloperoxiase activity and interleukin-6, as well as by a reduction in apoptosis. These findings were similar to those of the present study. In addition, other studies have reported that curcumin inhibits $\mathrm{H}^{+}, \mathrm{K}^{+}$-ATPase activity in models of gastric ulcer disease (23), and also that it inhibits histone acetylation (24). However, to the best of our knowledge, these aspects have not been investigated in combination. In addition, a number of these experiments were conducted in vitro or without the use of drugs as a positive control group. Therefore in the present study these effects were investigated in parallel, and in vivo studies were included.

Epigenetic modification, including DNA methylation, histone acetylation and RNA interference, is an important mechanism by which gene expression may be regulated. Histone acetylation is catalyzed by HATs, and its removal by histone deacetylases (HDACs). HATs and HDACs often function within the context of transcriptional activator and repressor complexes, respectively. Acetylation is generally associated with transcriptional activation and deacetylation to transcriptional repression (25). Studies have shown that curcumin leads to inhibition of histone acetylation of different tissues and cells, such as spinal cord and cardiac progenitor cells $(13,14)$. Curcumin was shown to prevent the formation of ulcer lesions and significantly reduced the expression of $\mathrm{H}^{+}, \mathrm{K}^{+}$-ATPase in the mucosa of rats (26). It was also shown to exhibit a variety of pharmacological effects, including antitumor, anti-inflammatory and anti-infectious activities. In the present study, curcumin was demonstrated to be a potent inhibitor of HAT (25), and UDAC, a typical inhibitor of HAT $(27,28)$ was regarded as a positive control. The results showed that curcumin represses the expression of the $\mathrm{H}^{+}, \mathrm{K}^{+}$-ATPase $\alpha$ subunit mRNA, the gastric $\mathrm{H}^{+}, \mathrm{K}^{+}$-ATPase $\alpha$ subunit protein and total acetylated histone $\mathrm{H} 3$. This suggests that curcumin inhibits $\mathrm{H}^{+}, \mathrm{K}^{+}$-ATPase transcription and expression, and that this is associated with inhibition of histone $\mathrm{H} 3$ acetylation.

Chromatin immunoprecipitation is a useful method for studying interactions between specific proteins, or modified forms of proteins, and a genomic DNA region. Histone modifications may be analyzed by ChIP followed by PCR of suspected target genes $(29,30)$. The current study developed a PCR-based ChIP assay in order to determine the effect of curcumin on the acetylation of histones in the $\mathrm{H}^{+}, \mathrm{K}^{+}$-ATPase gene promoter regions of gastric mucosa parietal cells. The results showed that curcumin decreased the acetylation of histone $\mathrm{H} 3$ at the site of the $\mathrm{H}^{+}, \mathrm{K}^{+}$-ATPase promoter in the ulcer model group compared with the control group, which indicated that curcumin may weaken the acetylation of histone $\mathrm{H} 3$ at the site of $\mathrm{H}^{+}, \mathrm{K}^{+}$-ATPase promoter gene, thus employing epigenetic modification effects in order to block the occurrence of gastric ulcer disease.

In conclusion, curcumin administration downregulated the acetylation of histone $\mathrm{H} 3$ at the site of the $\mathrm{H}^{+}, \mathrm{K}^{+}$-ATPase promoter gene, and inhibited the transcription and expression of the $\mathrm{H}^{+}, \mathrm{K}^{+}$-ATPase gene. This suggests that the anti-ulcer mechanisms of curcumin may be associated with its effects on the modulation of histone acetylation and deacetylation. As a potential anti-ulcer drug, curcumin has a number of significant advantages compared with current treatment. It is economic, safe, abundant and produces no obvious adverse reaction. Curcumin may therefore be a viable alternative to current therapies for gastric ulcer disease.

\section{Acknowledgements}

This study was supported by the Animal Experimental Center, Drum-Tower Hospital of Nanjing University and the State Key Laboratory of Pharmaceutical Biotechnology of Nanjing University. The authors would like to thank members of Xing laboratory for their technical assistance.

\section{References}

1. Gold BD, Colletti RB, Abbott M, et al: Helicobacter pylori infection in children: recommendations for diagnosis and treatment. J Pediatr Gastroenterol Nutr 31: 490-497, 2000.

2. McCullough P and Benson D: Acid-suppressive medication and hospital-acquired pneumonia. JAMA 302: 1415-1417, 2009.

3. Ali T, Roberts DN and Tierney WM: Long-term safety concerns with proton pump inhibitors. Am J Med 122: 896-903, 2009.

4. Hassall E, Owen D, Kerr W, et al: Gastric histology in children treated with proton pump inhibitors long term, with emphasis on enterochromaffin cell-like hyperplasia. Aliment Pharmacol Ther 33: 829-836, 2011.

5. Thong-Ngam D, Choochuai S, Patumraj S, Chayanupatkul M and Klaikeaw N: Curcumin prevents indomethacin-induced gastropathy in rats. World J Gastroenterol 18: 1479-1484, 2012.

6. Sharma AV, Ganguly K, Paul S, Maulik N and Swarnakar S: Curcumin heals indomethacin-induced gastric ulceration by stimulation of angiogenesis and restitution of collagen fibers via VEGF and MMP-2 mediated signaling. Antioxid Redox Signal 16: 351-362, 2012. 
7. Liu L, Sun L, Wu Q, et al: Curcumin loaded polymeric micelles inhibit breast tumor growth and spontaneous pulmonary metastasis. Int J Pharm 443: 175-182, 2013.

8. Shehzad A, Rehman G and Lee YS: Curcumin in inflammatory diseases. Biofactors 39: 69-77, 2013

9. Villaflores OB, Chen YJ, Chen CP, Yeh JM and Wu TY: Effects of curcumin and demethoxycurcumin on amyloid- $\beta$ precursor and tau proteins through the internal ribosome entry sites: a potential therapeutic for Alzheimer's disease. Taiwan J Obstet Gynecol 51: 554-564, 2012.

10. Mahattanadul S, Nakamura T, Panichayupakaranant $\mathrm{P}$, et al Comparative antiulcer effect of bisdemethoxycurcumin and curcumin in a gastric ulcer model system. Phytomedicine 16 342-351, 2009

11. Siddaraju MN and Dharmesh SM: Inhibition of gastric $\mathrm{H}(+), \mathrm{K}(+)$-ATPase and Helicobacter pylori growth by phenolic antioxidants of Curcuma amada. J Agric Food Chem 55: 7377-7386, 2007.

12. Zhang W and Kone BC: NF-kappaB inhibits transcription of the $\mathrm{H}(+)-\mathrm{K}(+)$-ATPase alpha(2)-subunit gene: role of histone deacetylases. Am J Physiol Renal Physiol 283: F904-F911, 2002.

13. Wang L, Sun H, Pan B, et al: Inhibition of histone acetylation by curcumin reduces alcohol-induced expression of heart development-related transcription factors in cardiac progenitor cells. Biochem Biophys Res Commun 424: 593-596, 2012.

14. Puglia C, Frasca G, Musumeci T, et al: Curcumin loaded NLC induces histone hypoacetylation in the CNS after intraperitoneal administration in mice. Eur J Pharm Biopharm 81: 288-293, 2012.

15. Li-jun J, Zhi-feng L, Mei Li et al: Preventive and therapeutic effects of curcumin on gastric ulcer in rats with stress. Journal of Applied Clinical Pediatrics 6: 451-453, 2009 (In Chinese).

16. Guth PH and Paulsen G: Aspirin-induced gastric injury in the rat: histologic changes and sucralfate cytoprotection. Proc Soc Exp Biol Med 184: 423-428, 1987.

17. Spicer Z, Miller ML, Andringa A, et al: Stomachs of mice lacking the gastric H,K-ATPase alpha-subunit have achlorhydria, abnormal parietal cells, and ciliated metaplasia. J Biol Chem 275 21555-21565, 2000.

18. Jackson SJ, Murphy LL, Venema RC, Singletary KW and Young AJ: Curcumin binds tubulin, induces mitotic catastrophe, and impedes normal endothelial cell proliferation. Food Chem Toxicol 60: 431-438, 2013.
19. Sun J, Han J, Zhao Y, Zhu Q and Hu J: Curcumin induces apoptosis in tumor necrosis factor-alpha-treated $\mathrm{HaCaT}$ cells. Int Immunopharmacol 13: 170-174, 2012.

20. Mahattanadul S, Reanmongkol W, Yano S, et al: Preventive and curative effects of curcumin on the development of gastric inflammatory diseases in rats. J Nat Med 60: 191-197, 2006.

21. Li YM, Lu GM, Zou XP, et al: Dynamic functional and ultrastructural changes of gastric parietal cells induced by water immersion-restraint stress in rats. World J Gastroenterol 12: 3368-3372, 2006.

22. Tuorkey M and Karolin K: Anti-ulcer activity of curcumin on experimental gastric ulcer in rats and its effect on oxidative stress/antioxidant, IL-6 and enzyme activities. Biomed Environ Sci 22: 488-495, 2009.

23. Huang J, Plass C and Gerhauser C: Cancer chemoprevention by targeting the epigenome. Curr Drug Targets 12: 1925-1956, 2011.

24. Kotb MA: Molecular mechanisms of ursodeoxycholic acid toxicity \& side effects: ursodeoxycholic acid freezes regeneration \& induces hibernation mode. Int J Mol Sci 13: 8882-8914, 2012

25. Balasubramanyam K, Varier RA, Altaf M, et al: Curcumin, a novel p300/CREB-binding protein-specific inhibitor of acetyltransferase, represses the acetylation of histone/nonhistone proteins and histone acetyltransferase-dependent chromatin transcription. J Biol Chem 279: 51163-51171, 2004.

26. Mei X, Xu D, Xu S, Zheng Y and Xu S: Novel role of $\mathrm{Zn}(\mathrm{II})$-curcumin in enhancing cell proliferation and adjusting proinflammatory cytokine-mediated oxidative damage of ethanol-induced acute gastric ulcers. Chem-Biol Interact 197: 31-39, 2012

27. Icardi L, De Bosscher K and Tavernier J: The HAT/HDAC interplay: multilevel control of STAT signaling. Cytokine Growth Factor Rev 23: 283-291, 2012.

28. Huang J, Plass C and Gerhauser C: Cancer chemoprevention by targeting the epigenome. Curr Drug Targets 12: 1925-1956, 2011.

29. Buro LJ, Shah S and Henriksen MA: Chromatin immunoprecipitation (ChIP) to assay dynamic histone modification in activated gene expression in human cells. J Vis Exp 29: 2053, 2010.

30. Pillai S and Chellappan SP: ChIP on chip assays: genome-wide analysis of transcription factor binding and histone modifications. Methods Mol Biol 523: 341-366, 2009. 